$\begin{array}{ll} & \text { Etnográfica } \\ \text { etnográfica } & \text { Revista do Centro em Rede de Investigação em }\end{array}$

Antropologia

vol. 15 (1) | 2011

Vol. $15(1)$

\title{
Construtores da bio(in)segurança na base de dados de perfis de ADN
}

Constructors of bio(in)security in the DNA profiles database

\section{Helena Machado}

\section{(2) OpenEdition}

\section{Journals}

\section{Edição electrónica}

URL: https://journals.openedition.org/etnografica/859

DOI: 10.4000/etnografica.859

ISSN: 2182-2891

\section{Editora}

Centro em Rede de Investigação em Antropologia

\section{Edição impressa}

Data de publição: 1 fevereiro 2011

Paginação: 153-166

ISSN: 0873-6561

\section{Refêrencia eletrónica}

Helena Machado, «Construtores da bio(in)segurança na base de dados de perfis de ADN», Etnográfica

[Online], vol. 15 (1) | 2011, posto online no dia 23 outubro 2011, consultado o 12 fevereiro 2022. URL: http://journals.openedition.org/etnografica/859 ; DOI: https://doi.org/10.4000/etnografica.859

\section{(c) (1) (8)}

Etnográfica is licensed under a Creative Commons Attribution-NonCommercial 4.0 International License. 


\section{Construtores da bio(in)segurança na base de dados de perfis de $\mathrm{ADN}^{1}$}

\section{Helena Machado}

O presente texto analisa discursos de peritos e de políticos produzidos acerca da criação de uma base de dados de perfis de ADN em Portugal para identificação civil e investigação criminal, com o intuito de explorar alguns patamares de construção da biossegurança. Constata-se que três tipos principais de argumentação são utilizados: a ciência como suporte de uma justiça simultaneamente mais eficaz e mais credível; a necessidade de acompanhar o percurso de países mais desenvolvidos em matéria de investigação criminal e de cooperação transfronteiriça; o contributo para o bem comum. Trata-se de um projeto técnico-genético e biopolítico crescentemente global e imbricado em imaginários coletivos assentes no medo do crime e do criminoso, que assenta mais em promessas de utilidade imaginada e de eficácia na identificação de criminosos do que na invocação dos riscos e das incertezas.

PALAVRAS-CHAVE: bases de dados, perfis de ADN, biossegurança, riscos.

\section{A GESTÃO SOCIAL DE INFORMAÇÃO GENÉTICA É HOJE OBJETO DE AMPLO debate, envolvendo políticos, juristas, cientistas e cidadãos. A reflexão aca- démica e discussão pública em torno dos efeitos sociais, económicos, éticos e políticos da utilização de novas tecnologias de identificação de indivíduos por perfis de ADN e do mapeamento e sequenciação dos genes terá atingido o seu ponto alto por via das consequências do desenvolvimento de projetos de}

1 Agradeço à Fundação para a Ciência e a Tecnologia o apoio concedido no âmbito do projeto de pós-doutoramento "Bases de dados genéticos com propósitos forenses, em Portugal: percursos, actores e discursos” (SFRH/BPD/34143/2006); e o apoio na transcrição e análise das entrevistas facultado por Ricardo André Santos Dias. Manifesto o meu vivo apreço pela avaliação crítica de uma primeira versão deste texto realizada por Susana Silva (FLUP) e por António Amorim (IPATIMUP). Agradeço ainda a Filipe Santos (CES-UC; UM) o cuidado empregue na revisão editorial do texto. Uma primeira versão destes conteúdos foi apresentada em formato de comunicação oral no colóquio internacional "Ambiguidades Contemporâneas da Segurança: Para Um Olhar de Perto”, 6 e 7 de maio de 2008, Lisboa, ISCTE. Agradeço os comentários a esta reflexão produzidos pelos participantes no debate. 
investigação genómica com amplas repercussões científicas, políticas e económicas, a nível global (Pálsson 2007).

Além da aplicação da genómica na medicina e nos cuidados de saúde, outro campo de potenciação de promessas reside na investigação criminal, prevenção e dissuasão do crime. A utilidade prometida dos usos desse tipo de tecnologia, associada a uma esperada aceitação dos seus benefícios por parte de diversos grupos sociais (Gamero et al. 2004), justifica, em grande medida, a crescente expansão e ampliação de bases de dados de perfis de ADN, um pouco por todo o mundo, tendo Portugal aprovado em 2008 legislação nessa matéria. ${ }^{2}$

Não deixa de ser ilustrativo da importância da crescente imbricação entre a ciência genómica e a política o facto de, no momento da apresentação dos primeiros resultados do projeto do genoma humano, ${ }^{3}$ a 26 de junho de 2000, o então presidente dos Estados Unidos Bill Clinton ter alegado estarmos a viver um momento histórico pelo qual iríamos, doravante, aprender "a linguagem de Deus, criadora da vida" (Gárcia-Sancho 2006: 16). Alguns anos mais tarde, no dia 1 de junho de 2007, o ministro da Justiça português Alberto Costa apresentou, nas instalações da Delegação do Sul do Instituto Nacional de Medicina Legal, em Lisboa, a proposta de lei de criação de uma base de dados de perfis de ADN com finalidades de investigação criminal e identificação civil. Referiu-se a esta medida como o mais eficaz instrumento "para a descoberta dos verdadeiros autores dos crimes e para a dedução de uma acusação bem sucedida", acrescentando: "Não menos importante, contribuirá para inocentar quem tenha sido injustamente acusado" (Costa 2007).

Embora distanciados temporal e geograficamente, e não obstante os distintos contextos sociopolíticos que separam as palavras de Bill Clinton e Alberto Costa, não será demasiado afirmar que um dispositivo retórico os une: a sustentação da crença de que os genes nos podem revelar algo que até há pouco transcendia a compreensão humana (Williams e Johnson 2004a), seja a verdade da essência humana (quem somos, quem seremos) ou a verdade da conduta humana (no caso em análise, quem é culpado e quem é inocente).

A mística associada ao gene (Nelkin e Lindee 1996) realça alguns aspetos culturais e políticos subjacentes a um projeto técnico-genético e biopolítico que converge com princípios mais amplos de controlo, avaliação e monitorização dos indivíduos. Essa inspeção dos cidadãos assenta na retórica do "avanço civilizacional”, ancorada na credibilidade conferida à ciência - neste caso, a

2 A Lei n. ${ }^{0}$ 5/2008 aprova a criação de uma base de dados de perfis de ADN para fins de identificação civil e criminal (Diário da República, $1 .^{a}$ série, n. $^{\circ}$ 30, 12 de fevereiro de 2008).

3 O Projeto do Genoma Humano (PGH) tem por objetivo o mapeamento e sequenciação do genoma humano e foi lançado em 1990 pelo Departamento de Energia e Institutos de Saúde dos Estados Unidos da América. Acabou por obter ressonância mundial, envolvendo outros países e indo ao encontro do objetivo de desenvolver meios para aplicar informação genética no estudo da biologia e da medicina, visando a descoberta e desenvolvimento de novos fármacos. 
genética forense - e no poder simbólico da justiça, a par com configurações atuais de cidadania que projetam modos de categorização e hierarquização dos cidadãos, dos criminosos aos cidadãos cumpridores. Pode então falar-se de uma cidadania genética enquanto conceito que descreve os processos múltiplos e complexos pelos quais indivíduos e grupos se envolvem e reconstroem as suas identidades pelos encontros com a biotecnologia (Rose e Novas 2005), e formando um conjunto de direitos e deveres associados a formas de vigilância e de controlo social baseadas no conhecimento científico e tecnológico dos genes.

No âmbito deste texto, proponho-me analisar alguns discursos produzidos a propósito da criação de uma base forense de dados de perfis de ADN em Portugal, com o intuito de explorar alguns patamares de construção da biossegurança. Entendo aqui biossegurança como forma de vigilância e de controlo social baseada no conhecimento científico e tecnológico da individualidade biológica do corpo humano (Ploeg 2002; Williams e Johnson 2004b), representando a criação e alargamento de bases de dados de perfis de ADN um elemento integrante e visível de um projeto técnico-genético e biopolítico crescentemente global e imbricado em imaginários coletivos assentes no medo do crime e do criminoso. Esta consciência do crime, em boa medida alimentada pela comunicação social e pela cultura popular (Owen 2007), é convocada sob a égide da busca do bem coletivo, pela promessa de segurança e tranquilidade e pela obtenção da "verdade" que permitirá identificar criminosos e ilibar inocentes. Interessa, pois, analisar os processos sociais de construção da verdade, mapear as motivações e interesses dos coconstrutores da mesma e também porque não? - discutir outras verdades possíveis.

Assistimos a um aparato de governância genómica (Gottweis 2005) que convoca, em simultâneo, diversos atores e sistemas de saberes e fazeres heterogéneos, e que assenta mais nas promessas de utilidade imaginada e de eficácia na identificação de criminosos do que na invocação dos riscos e das incertezas (Lentzos 2006). A sobrevalorização das promessas tecnológicas e a suavização dos riscos produzem determinados efeitos sociais, culturais e éticos que convergem para dispositivos retóricos destinados a apoiar mecanismos de construção da confiança pública.

A legitimação democrática torna-se um aspeto ideológico essencial para o sucesso dos projetos de bases de dados genéticos e na formação do discurso político "pelo qual os governos traduzem a sua visão política em programas e ações para produzir as mudanças desejadas no mundo real" (Cabinet Office 1999: 2.1.).

Partindo do ponto de vista dos atores sociais dominantes - políticos e peritos -, analisarei de que modo estes perspetivam o que consideram ser a verdade social, isto é, os fundamentos principais do projeto de construção de uma base de dados de perfis de ADN. Uma das assunções teóricas que guiarão esta reflexão parte do princípio de que estamos perante uma modalidade de interseção 
entre a justiça e a ciência que universaliza o ponto de vista dos dominantes com base em dois elementos principais que se entrecruzam para formar o que aqui designo por "dispositivo da universalidade": um primeiro fator diz respeito à afirmação da autonomia e da neutralidade, tanto do sistema científico como do sistema jurídico; um segundo fator refere-se à afirmação do distanciamento do conhecimento e ação dos peritos relativamente a agentes periciais dotados de menos recursos no campo da investigação criminal - nomeadamente polícias - e a leigos ou cidadãos comuns.

O dispositivo da universalidade alimenta-se tanto da verdade científica, aqui apoiada na crença no perfil de ADN como método de identificação individual inequívoco e universalmente estabelecido (Aas 2006) que pode revelar à justiça aquilo que, de outro modo, permaneceria oculto (Jasanoff 2006), como das funções esperadas da justiça, pelo cumprimento e aplicação da lei (igual para todos). A crença na universalidade está aliás amplamente difundida pelo senso comum, e como tal constitui "fator por excelência da eficácia simbólica" (Bourdieu 1989: 245).

\section{BIO(IN)SEGURANÇA PARTE I}

\section{— POLÍTICOS E PERITOS: QUEREMOS SER COMO OS OUTROS?}

Se os conceitos e terminologia usados para descrever e justificar os projetos de construção e desenvolvimento de bases de dados de perfis de ADN corresponderem às narrativas estabelecidas numa sociedade (Prainsack 2007), reforçam-se as categorias de pertença e de coletividade (Durkheim 1984 [1893]). A importância política da proteção face ao crime e do reforço da segurança (Garland 2001 ; Lyon 2001), ou da melhoria da justiça apoiada na ciência (McCartney 2006), bem como a pressão para acompanhar as tendências científicas globais no âmbito da harmonização de técnicas e procedimentos dos laboratórios forenses "apagando" os constrangimentos locais (Costa 2003), assumem nas sociedades de hoje uma espécie de natureza social e coletiva, como se estivesse presente em todos os indivíduos e de certo modo transcendendo-os (Durkheim 1984 [1893]).

A retórica da necessidade de empreender uma luta contra o crime e pela preservação da segurança afigura-se como devendo ser partilhada por todos os cidadãos respeitáveis. E, neste sentido, um dos elementos de defesa da necessidade de criação de uma base de dados de perfis de ADN é precisamente a proclamação do consenso social, veiculada pelo ministro da Justiça português, no referido discurso de apresentação pública desta medida do governo:

“O tema da criação de bases de perfis de ADN em Portugal concentra grandes expetativas em seu torno, quer na comunidade científica portuguesa, quer na opinião pública em geral [...] Estamos certos que o estabelecimento 
desta base de dados em Portugal constituirá um dos mais importantes passos na prevenção, deteção e dissuasão das atividades criminosas" (Costa 2007).

Estas palavras de enunciação da criação de bases de dados de perfis de ADN como um instrumento essencial para a identificação de criminosos e para a prevenção e dissuasão de atividades criminais são similares aos argumentos apresentados pelos governos de diferentes países em todo o mundo e no seio de maior ou menor contestação da parte dos comités de ética e comissões de defesa dos direitos humanos (Williams, Johnson e Martin 2004; NCB 2007).

Como já referido, a retórica política da legitimação das bases de dados de perfis de ADN ancora-se, entre outros elementos, na vocação de universalidade - tanto a universalidade da verdade da ciência, neste caso assente na ideia de que o perfil de ADN é único em cada indivíduo e, como tal, um meio identificatório por excelência, como na vocação universalística da justiça pela aplicação da lei para todos. As seguintes palavras do ministro da Justiça ilustram a legitimidade (também ela política) do processo pelo qual o sistema jurídico procura converter a "verdade" científica em potencial auxílio à decisão judiciária e usá-la como meio de aumentar a credibilidade do aparelho de justiça, ainda insuficientemente próximo daquilo que o próprio designa como "racionalidade cognitiva e instrumental":

"A Ciência Forense auxilia o Direito tornando a Justiça mais científica e mais rigorosa. A tecnologia forense referente ao estudo dos perfis genéticos de ADN constitui, como tem sido sublinhado, fonte de racionalidade cognitiva e instrumental. A credibilidade dos Tribunais e dos órgãos de investigação criminal sai reforçada pela utilização de um meio técnico com elevada precisão e fiabilidade: o uso da identificação por perfis genéticos" (Costa 2007).

Ao contrário das bases de dados de perfis de ADN recorrentemente apontadas como casos de sucesso - como as da Áustria, Escócia, Inglaterra e Irlanda do Norte, em que os perfis de indivíduos condenados podem ser conservados indefinidamente, ou as de Inglaterra e Irlanda do Norte, em que a inserção de perfis e sua manutenção sem limite temporal pré-definido acontece também em casos de simples suspeitos, mesmo após a sua ilibação -, em Portugal adotou-se uma solução de caráter restritivo em termos de inclusão de perfis e tempo de inserção: por um lado, apenas se inserem os perfis de indivíduos condenados por crime doloso a pena concreta de prisão igual ou superior a três anos (ainda que tenha sido substituída) e desde que haja despacho do juiz de julgamento determinando aquela inserção (n. ${ }^{\circ} 2$ do $\left.\operatorname{art}^{\circ}{ }^{\circ} 8^{\circ}\right)$. Por outro lado, os perfis são removidos na mesma data em que se procede ao 
cancelamento definitivo das respetivas decisões no registo criminal $\left(\mathrm{n} .{ }^{\mathrm{o}} \mathrm{l}, \mathrm{f}\right)$ do art. $\left.{ }^{\circ} 26 .^{\circ}\right)$.

Os peritos entrevistados testemunham a convicção de que, num "país como Portugal, de brandos costumes e baixa criminalidade", esta estratégia restritiva se afigurou como a mais adequada, pelo menos para já.

“Já foi um milagre conseguirmos esta lei. A base de dados perderá em termos de eficácia no início, mas eu sou a favor de começarmos devagarinho [...], mais valia começar devagarinho do que tentar tudo" [jurista].

"Penso que é preferível começar devagar e colocar isto em funcionamento correto e depois então, quando funcionar bem, alargar" [cientista].

Mas todos são unânimes em afirmar que, no futuro, irão ser alargados os critérios de inserção e retenção dos perfis de ADN na base de dados, estando esta crença assente numa espécie de profecia segundo a qual este instrumento irá em Portugal, indubitavelmente, seguir o caminho já traçado pelos países centrais:

"Daqui a dez anos vai aumentar, sim. Quando os tribunais virem que isto realmente funciona, vão os procuradores da República fazer pressão sobre os políticos para aumentar um bocadinho" [jurista].

"Vale mais começar como os projetos de outros países, que começaram com uma coisa mais pequena e depois alargaram. Todos os países começam com legislações mais restritas, $[. .$.$] e depois vão alargando progressivamente.$ A tendência é essa e tem uma certa lógica” [cientista].

O conceito de universalidade é passível de apropriações múltiplas por políticos, juristas ou cientistas (Bourdieu 1998) e é capaz de sustentar diferentes interesses segundo as posições e trajetórias dos atores sociais, que, no curso da ação, revelam interesses particulares na universalidade, invocando a razão, a verdade ou a virtude (Guibentif 2006). Formam-se, assim, dispositivos de manutenção da ordem, mas também de reprodução social, baseados, por um lado, na crença na precisão e na fiabilidade da genética, e, por outro, nas presumidas funções da justiça de identificar culpados e ilibar inocentes.

BIO(IN)SEGURANÇA PARTE II

— PERITOS E POLÍCIAS: SOMOS TODOS COMPETENTES?

A medicina forense e o direito afiguram-se como instâncias mediadoras e reprodutoras do modelo ideológico que sustenta as políticas de ordem e controlo social emanadas do Estado. No âmbito do tema aqui em análise, os modos 
de ação e de conhecimento acionados por cientistas e juristas são discutidos como elementos de um projeto técnico-genético e biopolítico assente num pacto social entre Estado e cidadãos que delimita direitos e deveres. Mas que também se alimenta, em larga medida, de um projeto de socialização da compreensão pública da ciência e tecnologia e do apelo à confiança pública (Silva 2008; Jones e Salter 2003).

A projeção de expetativas e benefícios atuais, e sobretudo futuros, da base de dados de perfis de ADN sustenta-se na construção do primado dos saberes e conhecimentos da ciência e na defesa da aproximação do direito ao ideal de objetividade e certeza desta (Costa 2003). Mas, no campo da investigação criminal e da desejada identificação de criminosos e ilibação de inocentes por intermédio da tecnologia de perfis de ADN, defrontam-se atores investidos de diferentes capacidades sociais e técnicas, ou, melhor dizendo, possuindo distintas capacidades reconhecidas de utilizar e interpretar a informação genética e também de "dizer o direito", enfim, de consagrar, como diria Pierre Bourdieu, “a visão legítima, justa, do mundo social” (Bourdieu 1989: 212).

Os peritos entrevistados realçam a importância da lei no estabelecimento de limites de ação e de competências, pelos quais sai não só reforçada a autoridade do Instituto Nacional de Medicina Legal (INML) pela custódia da base de dados de perfis de ADN, como também pelos poderes atribuídos aos juízes. À luz da Lei n. ${ }^{\circ} 5 / 2008$, os juízes são os únicos detentores de poder legal para ordenar a recolha de amostras biológicas e para determinar a inserção e remoção de um perfil da base de dados. Uma vez mais, reforça-se o caráter restritivo da base de dados de perfis de ADN em Portugal, quando comparada, por exemplo, com o caso de Inglaterra, em que a polícia detém amplos poderes para a recolha de amostras, tanto de suspeitos como de voluntários. ${ }^{4}$

Quando chamados a dar opinião sobre este acesso limitado e hierarquizado ao processo de recolha e inserção de perfis de $\mathrm{ADN}$, todos os entrevistados se mostraram favoráveis a este regime, invocando uma maior confiança nos modos de atuação dos juízes do que nos da polícia, no que diz respeito à garantia dos direitos individuais:

“É exatamente para controlar as liberdades e não haver abuso, e uma utilização abusiva de determinados meios de prova ou de obtenção de prova, como são as escutas telefónicas, como é a recolha de ADN, tudo isso está no

4 Os voluntários no Reino Unido para recolha de amostras biológicas para inserção em base de dados de perfis de ADN com intuitos forenses constituem uma figura diferente da do voluntário que consta da lei portuguesa. Embora não eliminando a hipótese de alguém se voluntariar espontaneamente para facultar uma amostra biológica para inserção de informação em base de dados genética com propósitos de investigação criminal, o voluntário no Reino Unido é mais correntemente alguém a quem a polícia solicita colaboração para recolha de amostra, que pode ser feita em massa em termos rotineiros ou no decurso de uma investigação específica. 
mesmo pacote, no fundo, e o juiz aparece como o garante das liberdades [...] nós pomos sempre o juiz a atuar e não pusemos os polícias a atuar, se é que compreende" [jurista].

"Se ficasse nas mãos das polícias poderia porventura haver algum desvirtuamento ou algum abuso da utilização destes dados" [cientista].

A hierarquização de autoridade que conduz à rigorosa delimitação de poderes da magistratura e da polícia é emblematicamente ilustrada pela seguinte narrativa de um jurista, que se refere à possibilidade de autonomia do juiz face a pressões externas e subsequente objetividade pelo facto de este assumir a função mais importante que é a de "dizer e aplicar o direito", ao contrário do polícia que tem que lidar diretamente com o criminoso. Enquanto que ao juiz está simbolicamente possibilitado um posicionamento "puro e neutro", o polícia está sujeito à "contaminação" pela proximidade física e psicológica ao crime, mesmo que deseje distanciar-se (Durão 2008).

"Quem vai para polícia é diferente de quem vai para magistrado, tem outra origem social, tem outra maneira de encarar, tem outra formação de base. Eles morrem, felizmente não muitos, mas podem morrer. Portanto a relação com o crime é necessariamente diferente de um magistrado que normalmente dorme descansado, não passa a noite acordado atrás de um bandido. O mais famoso procurador tem uma vida familiar tranquila, o PJ não, e portanto isso vai condicionar a relação psicológica com o criminoso" [jurista].

O reforço da idealização do papel do juiz surge por contraponto à "desconfiança" gerada em relação à polícia, a que corresponde uma espécie de concorrência entre o papel da magistratura no âmbito da administração estatal da justiça e outras formas alternativas de justiça que não detêm o poder de nomeação oficial, explícito e público:

"A polícia já usa estas coisas [bases de dados], às escondidas [...] o objetivo disto [criar uma base de dados de perfis de ADN] era regulamentar uma coisa que já existe, e que não existe no sítio certo, que é em institutos de medicina legal, existe é em laboratórios de polícias" [jurista].

Ao atribuir um papel preponderante ao juiz no âmbito da decisão sobre quem terá o seu perfil de ADN inserido na base de dados, subjugando a atuação policial ao poder da magistratura, esta lei mostra, de modo exemplar, como "a verdade social é o que está em jogo numa luta entre agentes armados de modo muito desigual" (Bourdieu 1989: 147). 
BIO(IN)SEGURANÇA PARTE III

\section{— PERITOS E LEIGOS: QUEREMOS TODOS O MESMO?}

A questão da legitimidade da violência simbólica remete-nos para questões éticas e jurídicas relacionadas com o consentimento, a privacidade e a integridade física e moral dos cidadãos. Como tal, a promoção política do uso deste tipo de tecnologia para a prevenção, deteção e investigação da criminalidade apoia-se em larga medida em argumentos em torno de conceitos como o consentimento informado e livre dos cidadãos, mas também na responsabilidade individual para o bem comum, pela ênfase na confiança, na dádiva e no altruísmo (Williams e Schroeder 2004) dos voluntários que venham a facultar amostras biológicas. Assim, na apresentação pública do projeto de constituição da base de dados, o ministro da Justiça colocava a tónica no facto de que "Não será criado nenhum ficheiro contendo perfis de ADN de arguidos", de modo a possibilitar a todos uma futura reinserção na sociedade; acrescentava ainda que "Há que pautar as bases de dados pelo respeito das exigências constitucionais, impedindo a violação dos direitos dos cidadãos e dos princípios fundamentais da cidadania e da vida democrática" (Costa 2007).

No âmbito da lei da base de dados de perfis de ADN, a recolha da amostra biológica é referida como sendo "não invasiva" (colheita da mucosa bucal) com o consentimento do titular $\left(\right.$ art. $\left.^{\circ} 10 .^{\circ}\right)$. No entanto, a lei omite as situações de recusa de consentimento e não apresenta qualquer salvaguarda especial em relação à recolha de amostras em menores e em incapazes. A eventualidade da recusa na recolha de amostra biológica em âmbito de investigação criminal é assim desvalorizada, como algo improvável. Na perspetiva de dois entrevistados - um cientista e um jurista -, a recusa de submissão ao ato médico para recolha de amostra biológica, ou se dá por ignorância dos visados (sendo dever do perito informar) ou pela existência de real culpa do arguido, e neste caso há que proceder à reparação desse "desvio", ou seja, o Estado poderá legitimamente socorrer-se da coerção física, em nome do bem coletivo ou pressupor culpabilidade com base na recusa:

"Geralmente ninguém se recusa, se devidamente informado. E se houver recusa, não faço. A não ser que seja por ordem judicial. Se o juiz ordenar, tenho que fazer" [cientista forense].

"O sujeito poder ser prejudicado por se recusar a consentir a recolha da amostra? O juiz pode pensar, você não quis fazer o teste, portanto é o criminoso, mas isso é um problema independente desta lei, isto já existe hoje em dia. Aí já é uma discussão que existe há muitos anos, se pode fugir, isto já é independente desta lei" [jurista]. 
A suavização dos riscos de compressão dos direitos individuais que está presente na lei da base de dados de perfis de ADN revela-se de modo exemplar na ideia de que a construção desse tipo de base de dados pode ser feita a partir de voluntários (n. ${ }^{\circ} 1$ do art. $^{\circ}{ }^{6} .^{\circ}$ ), que de forma "livre e informada" aceitem doar a sua "impressão digital genética", o que pode conduzir à criação de uma espécie de imperativo moral que surge num vazio de discussão das modalidades possíveis de consentimento e de certificação dos direitos dos participantes (Machado e Silva 2008).

O cientismo e progressismo tecnológico revelam-se tanto no discurso político de promoção da base de dados de perfis de ADN como nos discursos dos peritos entrevistados. De facto, as possíveis resistências a este projeto tecnológico, a origem dos problemas de resistência à inovação, são colocadas, não nos efeitos negativos ou indesejados da dinâmica científica e tecnológica, mas nas alegadas manifestações de ignorância, irracionalidade ou vulnerabilidade à manipulação por parte daqueles que resistem ao avanço tecnológico e se opõem ao progresso científico:

"Não podemos ser velhos do Restelo, ${ }^{5}$ sempre com medos. [A proposta de lei] foi objeto de críticas de pessoas que não sabiam nada sobre o tema. Nem queriam saber, não faziam um esforço para aprender e sempre me mostrei disponível para prestar esclarecimentos. [Na discussão da proposta de lei no Parlamento] apenas contestavam por motivos políticos" [cientista forense].

Reivindicando a sua supremacia cognitiva, os peritos encaram os argumentos "não científicos" e "não técnicos" (sociais, políticos, éticos, económicos) como intromissões ilegítimas num domínio que deve ser reservado aos especialistas e demarcado segundo os critérios destes (Nunes 2007). Mais ainda, quando questionados sobre a "desejável" composição do Conselho de Fiscalização das atividades associadas à base de dados de perfis de ADN, designado pela Assembleia da República e "composto por três cidadãos de reconhecida idoneidade" (n. 3 do art. $^{\circ} 29 .^{\circ}$ ), todos os peritos entrevistados foram unânimes na afirmação de que esta instância de controlo das atividades do INML não deve integrar "simples" leigos.

"[Quem deve integrar o Conselho de Fiscalização?] Na minha opinião devem ser especialistas. Não, não vejo necessidade de integrar os leigos" [jurista].

5 O "velho do Restelo" é uma personagem criada por Luís de Camões no canto IV de Os Lusíadas. Simboliza os pessimistas, os conservadores e reacionários que não acreditavam no sucesso da epopeia dos descobrimentos portugueses. No caso em apreciação, o entrevistado refere-se aos opositores dos avanços da ciência e das aplicações desta em prol do bem comum. 
A afirmação da autoridade dos peritos - juristas e cientistas - na condução do projeto de criação e desenvolvimento e na monitorização de uma base de dados de perfis de ADN baseia-se no distanciamento em relação aos leigos ou na sua convocação para atividades subordinadas, cuja exequibilidade é inclusive relativizada. Mas a consolidação da autoridade instituída fundamenta-se também na hierarquização dos atores no seio do campo da investigação criminal e na rigorosa delimitação no acesso e manuseamento da referida base. Trata-se de uma divisão social do trabalho, projetora de hierarquização de saberes e poderes e, como tal, delimitadora de competências.

\section{CONCLUSÃO}

O "portfólio de riscos" da base de dados de perfis de ADN em Portugal, enquanto mecanismo de seleção das ameaças e danos possíveis que deverão convocar a atenção da sociedade e de suavização de riscos e incertezas, segue uma determinada agenda política e cultural (Lentzos 2006). Delineia-se aqui uma espécie de apropriação privada do serviço público, na medida em que os peritos mobilizam a universalidade da ciência e da justiça para se apresentarem a si mesmos como servidores do interesse geral e distanciados de interesses particulares. Esse distanciamento é apenas aparente, na medida em que a mobilização da categoria da universalidade corresponde aos interesses dos poderes políticos (Bourdieu 1989), que, por sua vez, necessitam de especialistas em matéria científica (Jasanoff 2005) e jurídica (Gonçalves 1991) para consolidar a sua própria posição social.

Apesar de os dispositivos retóricos que sustentam tanto a ciência como a justiça se autofundamentarem pela invocação da autonomia, neutralidade e objetividade (Bourdieu 1998; Teubner 1993), todos os processos de seleção se baseiam em avaliações morais e se alimentam de normas culturais. No caso da base de dados de perfis de ADN, a mobilização e construção da legitimidade deste instrumento reside no apelo a um desejável casamento entre ciência e justiça, que no âmbito de uma ação concertada possa formar uma ferramenta poderosa na prevenção, deteção e investigação da criminalidade e, como tal, seja capaz de providenciar níveis adequados de segurança e de tranquilidade públicas. Deste modo, a legitimação política deste projeto técnico-genético e biopolítico passa por tentar conciliar interesses potencialmente conflituais, como a celebrização da ciência, a promoção da credibilidade da justiça e a defesa do interesse público (Jones e Salter 2003).

Associada à ideologia desenvolvimentista e mimética face aos países do centro desenvolvido da Europa, a justificação da importância de uma base de dados de perfis de ADN em Portugal representa um exemplo emblemático do que Bourdieu designa por violência simbólica legítima, “cujo monopólio 
pertence ao Estado e que se pode combinar com o exercício da força física" (Bourdieu 1989: 211).

A reivindicação de legitimidade e a construção das motivações para a obediência fundamenta-se no recrutamento dos mais qualificados na especialidade e na dominação por força do saber especializado. Aos dominados é pedida a obediência a atribuições racionalmente delimitadas conferidas por essa ordem social, em nome do progresso e da segurança e tranquilidade públicas.

Os dispositivos retóricos utilizados para a reivindicação da legitimidade da criação de uma base de dados de perfis de ADN em Portugal revestem-se de uma especificidade que foi objeto de particular ênfase no âmbito deste texto e que podemos sintetizar em três patamares: (i) mobilização política e governamental dos recursos e ações dos peritos do campo jurídico e do campo científico; (ii) autoafirmação da autonomia dos peritos e distanciamento face a atores mais desapossados no campo da investigação criminal; (iii) convocação dos leigos para participarem na luta contra o crime e de consolidação e defesa da segurança pública, mas na posição de servidores de um projeto coletivo que os convoca mas que também os transcende, em nome da desejável confiança no Estado, doravante apoiado na ideologia da neutralidade e na verdade da ciência e na vocação para a igualdade dos cidadãos e defesa da justiça.

Neste projeto de consolidação da biossegurança tem estado ausente a incorporação de mecanismos de participação e avaliação cívicas dos modos de organização e manutenção dos dados genéticos, surgindo o Estado como garante único do interesse público. Entrecruza-se, assim, a autoridade política com a autoridade jurídicocientífica, secundarizando-se de modo autoritário as epistemologias cívicas possíveis (Jasanoff 2005).

\section{BIBLIOGRAFIA}

AAS, Katja, 2006, “'The body does not lie': identity, risk and trust in technoculture”, Crime, Media, Culture, 2 (2): 143-158.

BOURDIEU, Pierre, 1989, O Poder Simbólico. Lisboa, Difel.

— 1 1998, Meditações Pascalianas. Oeiras, Celta Editora.

CABINET OFFICE, 1999, Modernising Government: White Paper, março, disponível em < http://www.archive.official-documents.co.uk/document/cm43/4310/4310-02.htm> (acesso em 17/06/2008).

COSTA, Alberto, 2007, discurso de apresentação da proposta de lei de criação de uma base de dados de perfis de ADN, 1 de junho, disponível em < http://www.mj.gov. 
pt/sections/informacao-e-eventos/arquivo/2-trimestre-de-2007/proposta-de-lei-que/> (acesso em 17/06/2008).

COSTA, Susana, 2003, A Justiça em Laboratório - A Identificação por Perfis Genéticos de ADN: entre a Harmonização Transnacional e a Apropriação Local. Coimbra, Almedina.

DURÃO, Susana, 2008, "A rua dos polícias: visão itinerante”, em Graça Índias Cordeiro e Frédéric Vidal (orgs.), O Lugar da Rua. Lisboa, Livros Horizonte, 79-96.

DURKHEIM, Émile, 1984 [1893], Da Divisão do Trabalho Social, vol. I. Lisboa, Presença.

GAMERO, Joaquín Jose et al., 2004, "DNA technology application procedures in forensic practice: social and ethical conditioning II”, International Congress Series, 1261: 571 $-573$.

GARCÍA-SANCHO, Miguel, 2006, "The rise and fall of the idea of genetic information", Genomics, Society and Policy, 2 (3): 16-36.

GARLAND, David, 2001, The Culture of Crime Control. Oxford, Oxford University Press.

GONÇALVES, Maria Eduarda, 1991, "Ciência e direito: de um paradigma a outro", Revista Crítica de Ciências Sociais, 31: 89-113.

GOTTWEIS, Herbert, 2005, "Governing genomics in the $21^{\text {st }}$ century: between risk and uncertainty", New Genetics and Society, 24 (2): 175-193.

GUIBEnTIF, Pierre, 2006, Teorias Sociológicas Comparadas e Aplicadas: Bourdieu, Foucault, Habermas e Luhmann Face ao Direito, lição de síntese apresentada no âmbito de provas de agregação. Lisboa, ISCTE.

JASANOFF, Sheila, 2005, Designs on Nature: Science and Democracy in Europe and the United States. Princeton, Princeton University Press.

— 2006, "Just evidence: the limits of science in the legal process", Journal of Law, Medicine \& Ethics, 34 (2): 328-341.

JONES, Mavis, e Brian SALTER, 2003, "The governance of human genetics: policy discourse and constructions of public trust”, New Genetics and Society, 22 (1): $21-41$.

LENTZOS, Filippa, 2006, "Rationality, risk and response: a research agenda for biosecurity", BioSocieties, 1 (4): 453-464.

LYON, David, 2001, Surveillance Society: Monitoring Everyday Life. Buckingham, Open University Press.

MACHADO, Helena, e Susana SILVA, 2008, "A Portuguese perspective: commentary on the Nuffield Council on Bioethics report 'The forensic use of bioinformation: ethical issues'", BioSocieties, 3 (1): 99-101.

McCARTNEY, Carole, 2006, Forensic Identification and Criminal Justice: Forensic Science, Justice and Risk. Cullompton, Willan.

NCB, 2007, The Forensic Use of Bioinformation: Ethical Issues, Nuffield Council on Bioethics, disponível em <http://www.nuffieldbioethics.org/fileLibrary/pdf/The_forensic_use_of_ bioinformation_-_ethical_issues.pdf> (acesso em 17/06/2008).

NELKIN, Dorothy, e Susan LINDEE, 1996, The DNA Mystique: The Gene as a Cultural Icon. Nova Iorque, W. H. Freeman.

NUNES, João Arriscado, 2007, Governação, Conhecimentos e Participação Pública, relatório apresentado para provas públicas de agregação em Sociologia à Faculdade de Economia da Universidade de Coimbra.

OWEN, Tim, 2007, "Culture of crime control: through a post-foucauldian lens", Internet Journal of Criminology, disponível em <http://www.internetjournalofcriminology.com /ijcarticles.html> (acesso em 19/06/2008). 
PÁLSSON, Gísli, 2007, Anthropology and the New Genetics. Cambridge e Nova Iorque, Cambridge University Press.

PLOEG, Irma Van der, 2002, "Biometrics and the body as information: normative issues of the socio-technical coding of the body", em David Lyon (org.), Surveillance as Social Sorting: Privacy, Risk, and Digital Discrimination. Londres e Nova Iorque, Routledge, 57-73.

PRAINSACK, Barbara, 2007, "Research populations: biobanks in Israel", New Genetics and Society, 26 (1): 85-103.

ROSE, Nikolas, e Carlos NOVAS, 2005, "Biological citizenship", em Aihwa Ong e Stephen Collier (orgs.), Global Assemblages: Technology, Politics and Ethics as Anthropological Problems. Oxford, Blackwell Publishing, 439-463.

SILVA, Susana, 2008, “Consentir incertezas: o consentimento informado e a (des)regulação das tecnologias de reprodução assistida”, Cadernos de Saúde Pública, 24 (3): 525-534.

TEUBNER, Gunther, 1993, O Direito como Sistema Autopoiético. Lisboa, Fundação Calouste Gulbenkian.

WILLIAMS, Garrath, e Doris SCHROEDER, 2004, "Human genetic banking: altruism, benefit and consent", New Genetics and Society, 23 (1): 89-103.

WILLIAMS, Robin, e Paul JOHNSON, 2004a, "Wonderment and dread: representations of DNA in ethical disputes about forensic DNA databases", New Genetics and Society, 23 (2): 205-223.

—, 2004b, "Circuits of surveillance", Surveillance and Society, 2 (1): 1-14.

WILliamS, Robin, Paul JOHNSON, e Paul MARTIN, 2004, Genetic Information and Crime Investigation, disponível em < http://www.dur.ac.uk/resources/sass/sociology/Genetic\%20 Information\%20\&\%20Crime\%20Investigation.pdf> (acesso em 17/06/2008).

Constructors of bio(in)security in the DNA profiles database - Helena Machado - Departamento de Sociologia da Universidade do Minho; Centro de Estudos Sociais da Universidade de Coimbra, Portugal • hmachado@ics.uminho.pt

This paper analyses the discourses produced by experts and politicians about the creation of a DNA database for civil identification and criminal investigation purposes in Portugal, aiming to explore some stances in the construction of biosecurity. Three main types of arguments are found: science as the support of a simultaneously more effective and reliable justice; the need to follow the course of more developed countries in terms of criminal investigation and trans-border cooperation; the contribution towards the common good. This concerns an increasingly global technical-genetic and biopolitical project, merged within collective imageries built upon on fears of crime and criminals, which is more grounded on promises of imagined utility and efficacy in the identification of offenders than on the invocation of the risks and uncertainties.

KEYWORDS: databases, DNA profiles, biosecurity, risks. 